\title{
Treatment targets of exercise for persistent non- specific low back pain: a consensus study
}

Citation for published version (APA):

Wood, L., Bishop, A., Lewis, M., Smeets, R. J. E. M., Bronfort, G., Hayden, J. A., \& Foster, N. E. (2021). Treatment targets of exercise for persistent non-specific low back pain: a consensus study.

Physiotherapy, 112, 78-86. https://doi.org/10.1016/j.physio.2021.03.005

Document status and date:

Published: 01/09/2021

DOI:

10.1016/j.physio.2021.03.005

Document Version:

Publisher's PDF, also known as Version of record

Document license:

Taverne

Please check the document version of this publication:

- A submitted manuscript is the version of the article upon submission and before peer-review. There can be important differences between the submitted version and the official published version of record.

People interested in the research are advised to contact the author for the final version of the publication, or visit the DOI to the publisher's website.

- The final author version and the galley proof are versions of the publication after peer review.

- The final published version features the final layout of the paper including the volume, issue and page numbers.

Link to publication

\footnotetext{
General rights rights.

- You may freely distribute the URL identifying the publication in the public portal. please follow below link for the End User Agreement:

www.umlib.nl/taverne-license

Take down policy

If you believe that this document breaches copyright please contact us at:

repository@maastrichtuniversity.nl

providing details and we will investigate your claim.
}

Copyright and moral rights for the publications made accessible in the public portal are retained by the authors and/or other copyright owners and it is a condition of accessing publications that users recognise and abide by the legal requirements associated with these

- Users may download and print one copy of any publication from the public portal for the purpose of private study or research.

- You may not further distribute the material or use it for any profit-making activity or commercial gain

If the publication is distributed under the terms of Article $25 \mathrm{fa}$ of the Dutch Copyright Act, indicated by the "Taverne" license above, 


\title{
Physiotherapy
}

Physiotherapy 112 (2021) 78-86

\section{Treatment targets of exercise for persistent non-specific low back pain: a consensus study}

\author{
Lianne Wood ${ }^{\mathrm{a}, \mathrm{b}, *}$, Annette Bishop ${ }^{\mathrm{a}}$, Martyn Lewis ${ }^{\mathrm{a}}$, Rob J.E.M Smeets ${ }^{\mathrm{c}, \mathrm{d}}$, \\ Gert Bronfort $^{\mathrm{e}}$, Jill A. Hayden ${ }^{\mathrm{f}}$, Nadine E. Foster ${ }^{\mathrm{a}}$ \\ a Primary Care Centre Versus Arthritis, School of Primary, Community and Social Care, Faculty of Medicine and Health Sciences, \\ Keele University, Newcastle-under-Lyme ST5 5BG, UK \\ ${ }^{\mathrm{b}}$ Nottingham University Hospitals NHS Trust, Queens Medical Centre, Derby Road, Nottingham NG 2UH, UK \\ ${ }^{\mathrm{c}}$ Department of Rehabilitation Medicine, Research School Functioning, Participation \& Rehabilitation, CAPHRI, Maastricht \\ University Maastricht, The Netherlands \\ ${ }^{\mathrm{d}}$ CIR Revalidatie, Eindhoven, The Netherlands \\ ${ }^{\mathrm{e}}$ Earl E Bakken Centre for Spirituality and Healing, University of Minnesota, Minneapolis, MN 55455, USA \\ ${ }^{\mathrm{f}}$ Department of Community Health and Epidemiology, Dalhousie University, 5790 University Avenue, Halifax, NS B3H 1V7, \\ Canada
}

\begin{abstract}
Objectives Despite several hundred previous randomised controlled trials (RCTs), the key treatment targets of exercise for persistent nonspecific low back pain (NSLBP) remain unclear. This study aimed to generate consensus about the key treatment targets of exercise interventions for patients with NSLBP.

Design Consensus was generated using modified nominal group technique in two, sequential, workshops. The results of a previous systematic review informed the first, national, workshop idea generation and the results of this workshop informed the second, international, workshop. The authors generated a starting list of 30 treatment targets from the systematic review. A pre-specified consensus threshold of $75 \%$ was used in the voting stage.

Participants Workshop participants included people with experience of using exercise to manage their persistent NSLBP, clinicians who prescribe exercise for persistent NSLBP, and researchers who design and evaluate exercise interventions in RCTs. All participants generated, voted and ranked the treatment targets in each workshop using an online platform.

Results A total of 39 participants contributed to the consensus (15 in the national workshop and 24 in the international workshop), comprising two people with NSLBP, six clinicians and 31 researchers/clinicians. A total of 40 exercise treatment targets were generated, and 25 were retained after voting and ranking. The prioritised targets of exercise for persistent NSLBP were: improving function, improving quality of life, reducing pain, meeting patient-specific goals and reducing fear of movement.

Conclusions Future RCTs of exercise should specify the targets of their exercise intervention and consider assessing these treatment targets as well as including mediation analyses.
\end{abstract}

(C) 2021 Chartered Society of Physiotherapy. Published by Elsevier Ltd. All rights reserved.

Keywords: Exercise; Treatment targets; Low back pain; Consensus workshop

\footnotetext{
* Corresponding author at: Primary Care Centre Versus Arthritis, School of Primary, Community and Social Care, Faculty of Medicine and Health Sciences, Keele University, Newcastle-under-Lyme ST5 5BG, UK.

E-mail address: 1.wood2@keele.ac.uk (L. Wood). URL: @WoodWicksLianne (L. Wood).
}

\section{Introduction}

Exercise is a core recommended treatment for persistent non-specific low back pain (NSLBP) [1-3], although no single approach to exercise is consistently superior over others $[4,5]$. There is strong evidence that exercise has moderate 
benefits for pain and function in the short-term [6-8]. Exercise is a subgroup of physical activity, which is planned, repeated, structured and intends to improve one's physical fitness [9]. Regular and adequate levels of physical activity have significant health benefits at all ages: improving muscular and cardiorespiratory fitness, bone and functional health; preventing falls and depression; improving general cardiovascular health; and maintaining energy levels and weight control [9]. Exercise may reduce the severity of chronic pain as well, and lead more generally to improved overall physical and mental health, and physical functioning [10]. However, the biological targets and mechanisms of action of exercise in persistent NSLBP are not fully understood nor yet agreed within the clinical and research community of NSLBP [11]. A treatment target should reflect the aims and or goals of the intervention(s) [12], but in the field of persistent NSLBP, the treatment targets of exercise are poorly defined compared to other fields of healthcare such as coronary heart disease $[13,14]$ and diabetes $[15,16]$.

A recent systematic review [17] identified numerous direct and indirect treatment targets from published trials of exercise for persistent NSLBP. Only $67 \%$ of included trials specified a clear rationale for their exercise intervention, while $22 \%$ indirectly inferred treatment targets from the language used to describe the rationale for the exercise interventions. However, there was considerable heterogeneity between exercise types and treatment targets identified, confirming a lack of consensus about the treatment targets of exercise for persistent NSLBP. The most frequently reported treatment targets were reducing pain (nine trials), improving spinal stabilisation (eight trials) and muscle strengthening (eight trials) [17]. Furthermore, even trials that evaluated similar exercise approaches, for example, the McKenzie approach [18,19] described different treatment targets. This study aimed to generate consensus among major stakeholders about the key treatment targets of exercise interventions for patients with persistent NSLBP.

\section{Methods}

\section{Design}

Consensus was generated using modified nominal group technique in two, sequential, workshops as part of an exploratory study. The nominal group methodology was selected as it has previously been successfully used when incorporating both researchers, clinicians and patients, and ensures that the voices of all participants are heard and included [20]. Each workshop moved through five stages: introduction, idea generation, idea sharing, group discussion, voting and ranking [21], modified for each of two workshops in this study. The final ranking stage provided consensus as an aggregation of the participants' views rather than a communal viewpoint [22]. Ethical approval was obtained from the University Research Ethics committee for both workshops.

\section{Participants}

This study included people with lived experience of using exercise to manage their persistent NSLBP, clinicians who prescribe exercise for persistent NSLBP, and researchers who design and evaluate exercise interventions for NSLBP in trials. The authors set a limit of 25 participants per workshop to ensure manageable group discussion and input as part of the workshop process [23]. The first, national, workshop (October 2018) targeted clinicians (predominantly physiotherapists), people who had used exercise, and researchers (as described above) by using advertisements, telephone calls, targeted emails, social media, and contact with local patient groups for arthritis and back pain. Despite extensive advertisement, few people with a lived experience of using exercise for NSLBP enquired for this study. The second, international, workshop was held as part of an international conference (June 2019): The International Forum for Back and Neck Pain Research in Primary Care, held in Quebec City, Canada. This workshop targeted researchers who may or may not also be clinicians.

\section{Workshop process}

Both workshops began with silent idea generation. The national workshop was informed by a systematic literature review [17], and the results of the national workshop informed the international workshop. Fig. 1 summarises the study process, and each of the stages is outlined below. During the workshop processes, the stages were not always completed sequentially, as portrayed in Fig. 1 with order delineated by the stage number above each workshop process.

\section{National workshop}

\section{Pre-workshop (stages 1 and 2)}

Participants provided informed consent and baseline demographic information online on registering for the workshop. Before the workshop, access to the online portal was provided through GroupMap to view the list of pre-generated treatment targets. Participants were able to add to this, as desired, prior to the workshop. Participants' additions were private to the rest of the group until the workshop. Idea generation items that were similar were merged by the research team to avoid duplication, and a total list of all potential treatment targets generated was created at the end of this process.

\section{Within workshop (stages 3-5)}

Participants were able to participate virtually through the use of Skype (Skype Communications S.a r.1.) or face-to-face. All participants in the workshop brought a mobile device to engage with the online platform during the workshop. The workshop took two hours. The results of the idea generation stage were visually displayed to all participants, with the opportunity to add any omitted items to the list, and for discussion of items displayed. Due to the range of participants 


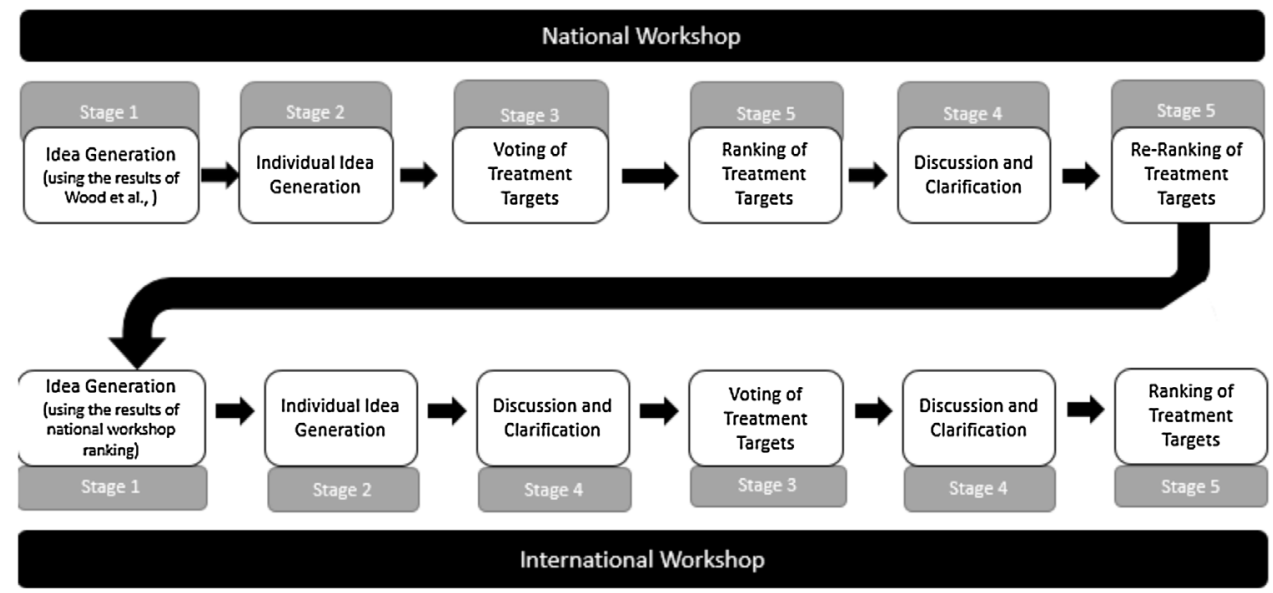

Fig. 1. Flow chart of consensus workshop stages (modified from Potter et al., 2004).

and the number of additional constructs added in the second stage, discussion of the individual potential treatment targets was delayed until after the voting and ranking had reduced the number of targets. Participants then privately voted (yes/no) for their ten most important treatment targets (stage 3) using the online platform. The potential treatment targets that obtained at least one vote were carried through to the next stage and were presented to the group via the online platform. No thresholds for consensus were used within this workshop as it was the first stage in an exploratory study. Items were then individually ranked in order of importance through an online ranking process (stage 5) where participants allocated ten points to their most important treatment target, descending to one point for the least important. The results of this ranking process were discussed within the workshop (stage 4): treatment targets were discarded, grouped and amended as required through discussion and verbal agreement from the workshop participants. A further ranking stage was undertaken online two weeks after the workshop due to the delayed discussion and clarification stage.

\section{International workshop}

\section{Pre-workshop (stages 1 and 2)}

Before the workshop, registered attendees provided informed consent and baseline demographic information. They were also supplied with a list of the final ranked treatment targets from the national workshop and asked to add any other potential treatment targets. Google sheets was used to develop these online forms.

\section{Within workshop (stages 3-5)}

The results of the idea generation were presented to the workshop participants visually, allowing the opportunity for potential treatment targets of a similar construct to be clarified and grouped, discarded or amended as agreed by the group. Voting (stage 3), occurred individually on a document developed on Google Sheets; participants were able to vote for any number of items they felt to be potential treatment tar- gets (yes/no). In the voting stage, a pre-specified consensus threshold of $75 \%$ was set for items where $75 \%$ of participants agreed that the item was not a treatment target of exercise [24]. These treatment targets were excluded from future voting and ranking rounds. All targets meeting the pre-specified consensus threshold were carried through to the next stage for ranking. There was then further discussion and clarification (stage 4) before participants individually ranked the treatment targets in order of priority (stage 5). Ranking occurred in order of importance from one to ten and amended to reflect the same scaling as in the national workshop (i.e. the greatest score has the most importance). The results were then presented to the participants of the workshop, who agreed with the order of importance of treatment targets, and declined the opportunity to re-rank treatment targets. These were then grouped into functional (relating to physical function), psychosocial (including psychological and social), behavioural (for example health service use) and impairment-based (such as strength or flexibility) targets [25].

\section{Results}

\section{Participants}

A total of 39 participants contributed to the consensus workshops (15 in the national workshop and 24 in the international workshop). A total of 32 participants completed all stages of each workshop (12 in the national workshop, and 20 in the international workshop). Participants of the two workshops were from ten different countries (UK, Canada, Brazil, USA, Australia, Denmark, Finland, Norway, Sweden, Netherlands). Ninety percent of participants had experienced NSLBP at some point in their lives. Demographic information is summarised in Table 1 below for 36 of the 39 participants. Three participants in the national workshop were unable to take part in the workshop but completed the preworkshop idea generation and post-workshop ranking. Only 21 participants provided baseline demographic data in the 
Table 1

Demographic information of workshop participants.

\begin{tabular}{lll}
\hline & National (\%) & International (\%) \\
\hline $\begin{array}{l}\text { Total participants } \\
\text { Gender (female) }\end{array}$ & $15($ range 12 to 15) & 21 (range 20 to 24) $)^{\mathrm{a}}$ \\
$\begin{array}{l}\text { Participation type: } \\
\text { Face-to-face }\end{array}$ & $7(47)$ & $13(62)$ \\
$\quad$ Virtual & $8(53)$ & $21(20$ to 24) \\
$\begin{array}{l}\text { Profession: } \\
\text { Clinical background }\end{array}$ & $12(80)$ & 0 \\
$\quad$ Type: & $10(67)$ & $19(90)$ \\
$\quad$ Physiotherapist & $1(6)$ & $12(57)$ \\
$\quad$ Chiropractor & $0(0)$ & $2(10)$ \\
$\quad$ Medical doctor & $1(6)$ & $4(19)$ \\
$\quad$ Other clinical & $6(38)^{\mathrm{b}}$ & $1(5)$ \\
Researchers & & $21(100)$ \\
Number of exercise & & \\
interventions developed & & $10(48)$ \\
$\quad<1$ & 3 & $9(43)$ \\
2 to 5 & 3 & $2(10)$ \\
$>5$ & $0^{\mathrm{c}}$ & $18(86)$ \\
People with lived & $14(93)$ & 10 \\
experience of NSLBP & & \\
Countries represented & 2 &
\end{tabular}

${ }^{a}$ Number represents participants in the first stage; range is represented due to the different number of participants across the stages.

b All six researchers involved in the national workshop had a clinical background or worked as clinicians.

c Only six researchers took part in the first workshop, and none had been involved in developing more than 5 exercise interventions.

international workshop due to the nature of the conference environment.

\section{National workshop results}

\section{Idea generation (stage 1-2)}

Fifteen participants completed the pre-meeting idea generation for the workshop. A further 25 treatment targets were added to the original list of 30 targets (informed by the previous systematic review [17]), creating a total list of 55 treatment targets (see Appendix 1 in supplementary material).
Voting of treatment targets (stages 3)

Discussion and clarification of the potential treatment targets were delayed until after the ranking stage (stage 5). Twelve participants voted for their ten most important potential treatment targets. At least half of the participants voted for 'reducing pain' (66.7\%), reducing fear of movement $(50 \%)$ and increasing functional capacity $(50 \%)$. Only 43 potential targets received votes and were carried through to the next stage, as seen in Appendix 2 in supplementary material.

\section{Ranking and discussion of treatment targets (stage 4 and 5)}

As the grouping stage had not been performed adequately in stage 4, significant overlap remained across treatment targets during the ranking stage (e.g. most important was reduce pain, second most important was reduce back pain). Three constructs were removed. Grouping of targets was performed, with an average of 2.4 (range 1-7) linked targets to a potential treatment target. This reduced the list of treatment targets from 43 to 18 (see Appendix 3 in supplementary material). For example, "increase physical function" was grouped with "reduce disability" and "increase functional capacity". Re-ranking of the 18 potential treatment targets was then performed online two weeks after the workshop with all participants who initially consented to participation $(n=15)$ with the final ranking results summarised in Table 2.

\section{International workshop results}

\section{Idea generation (stages 1-2)}

Twenty-one participants completed the pre-meeting idea generation for this workshop and added a further 15 targets to the original list of 18 treatment targets (Appendix 4 in supplementary material).

\section{Voting of treatment targets (stages 3-4)}

A total of 24 participants voted for treatment targets from the list of 33 potential treatment targets. The potential treat-

Table 2

National workshop final ranking results.

\begin{tabular}{|l|l|l|l|l|}
\hline \multicolumn{5}{|c|}{ National Workshop (n=15) } \\
\hline Rank & Treatment Target & Total Score & $\begin{array}{l}\text { No. of Top } \\
\text { 10 Rankings }\end{array}$ & \% in Top 3 \\
\hline 1 & Reduce pain & 120 & 14 & 67 \\
\hline 2 & Increase physical function* & 109 & 15 & 60 \\
\hline 3 & Reduce fear of movement & 100 & 15 & 47 \\
\hline 4 & Encourage normal movement & 74 & 11 & 27 \\
\hline 5 & Improve mobility & 60 & 9 & 27 \\
\hline 6 & Improve self-efficacy & 56 & 10 & 20 \\
\hline 7 & Enhance self-management skills & 54 & 10 & 13 \\
\hline 8 & Prevent recurrence & 45 & 9 & 13 \\
\hline 9 & Improve general health and well-being & 38 & 10 & 13 \\
\hline 10 & Improve strength & 29 & 6 & 0 \\
\hline
\end{tabular}

The total score could range from 0 to $150(0=$ worst attainable score, $150=$ best attainable score $)$; number of top ten rankings ranged from 0 to $15(0=$ least, $15=$ highest $)$. The maximal number of top ten rankings was 15 . * Physical function refers in this instance to activity limitation and participation restrictions [26]. Treatment targets are broadly grouped into blue (functional), green (behavioural), orange (impairment based), and pink (psychosocial) constructs. Recurrence, general health and wellbeing, and pain were not coloured as there were no similar constructs to be grouped with. 
Table 3

Final list of prioritised treatment targets.

\begin{tabular}{|c|c|c|c|c|}
\hline \multicolumn{5}{|c|}{ International Workshop $(\mathrm{n}=\mathbf{2 0})$} \\
\hline Rank & Treatment Target & Total Score & $\begin{array}{l}\text { No. of Top } 10 \\
\text { Rankings }\end{array}$ & $\%$ in Top 3 \\
\hline 1 & Increase functional ability & 110 & 14 & 50 \\
\hline 2 & Improve quality of life & 109 & 16 & 40 \\
\hline 3 & Reduce pain & 91 & 14 & 40 \\
\hline 4 & Patient specific targets/goals & 82 & 13 & 30 \\
\hline 5 & Reduce fear of movement & 82 & 15 & 20 \\
\hline 6 & Increase physical activity & 81 & 12 & 5 \\
\hline 7 & Improve self-efficacy & 71 & 13 & 20 \\
\hline 8 & Enhance self-management skills & 66 & 12 & 5 \\
\hline 9 & Improve work capacity & 53 & 12 & 10 \\
\hline 10 & Improve attitudes/cognitions/beliefs & 48 & 9 & 5 \\
\hline 11 & Reduce catastrophizing & 44 & 9 & 5 \\
\hline 12 & Prevent recurrence & 42 & 9 & 10 \\
\hline 13 & Improve social participation & 35 & 5 & 10 \\
\hline 14 & Reduce anxiety and depression & 25 & 5 & 0 \\
\hline 15 & Reduce other health services use & 24 & 7 & 0 \\
\hline 16 & Improve sleep & 23 & 5 & 10 \\
\hline 17 & Allow behavioural change & 16 & 5 & 0 \\
\hline 18 & Increase body awareness & 15 & 3 & 0 \\
\hline 19 & Improve strength & 14 & 3 & 0 \\
\hline 20 & Increase exercise capacity & 13 & 4 & 5 \\
\hline 21 & Improve motor control & 13 & 3 & 5 \\
\hline 22 & Increase body image & 8 & 1 & 5 \\
\hline 23 & Improve spinal mobility & 4 & 2 & 0 \\
\hline 24 & Weight loss/gain & 3 & 1 & 0 \\
\hline 25 & Increase trunk muscle endurance & 2 & 1 & 0 \\
\hline 26 & Improve cognitive function & 0 & 0 & 0 \\
\hline 27 & Lower inflammation & 0 & 0 & 0 \\
\hline
\end{tabular}

Treatment targets are broadly grouped into blue (functional), green (behavioural), orange (impairment based), and pink (psychosocial) constructs. Quality of life, recurrence and pain were not coloured as there were no similar constructs to be grouped with. Total score ranged from 0 to $200(0=$ worst attainable score, $200=$ best attainable score); number of top ten rankings ranged from 0 to $20(0=$ least, $20=$ highest $)$.

ment targets that received the most votes were 'reducing fear of movement' (92\%), 'increasing function' (87\%), 'improving self-efficacy' (87\%), 'reducing anxiety and depression' $(87 \%)$ and 'improving quality of life' $(87 \%)$. No potential treatment targets met the pre-specified criteria for exclusion. Potential treatment targets of a similar construct were clarified and grouped, discarded or amended as agreed by consensus of the group. Six items were removed during this stage, including 'general health and well-being' which was grouped within 'improved quality of life'.

\section{Ranking of treatment targets (stage 5)}

Twenty-five of twenty-seven treatment targets received sufficient votes for prioritisation. Twenty participants ranked the final list of prioritised treatment targets, as displayed in Table 3. Four psychological constructs were prioritised, three functional constructs and one impairment construct, as well as reducing pain and improving quality of life were included in the top ten. Participants declined the opportunity to perform a further ranking.

\section{Discussion}

\section{Principal findings}

With 39 participants from ten countries, this consensus study found that 1) increasing functional ability, 2) improv- ing quality of life, 3) reducing pain, 4) patient-specific targets and 5) reducing fear of movement, were the most important treatment targets of exercise interventions for patients with persistent NSLBP. The two sequential workshops generated consensus from people with lived experience of NSLBP, clinicians and researchers involved in developing exercise interventions in clinical practice and in trials of persistent NSLBP. From an initial list of 30 treatment targets informed by a systematic review [17], participants ranked a final list of 27 treatment targets. Psychosocial constructs (40\%) and functional constructs (30\%) were prioritised in the top ten treatment targets.

\section{Consideration of the findings in relation to other studies}

This study is the first, to our knowledge, to develop consensus about the treatment targets of exercise for persistent NSLBP with key stakeholders involved in developing, delivering and participating in exercise interventions. The results are similar to the treatment targets of exercise for persistent NSLBP suggested by Rainville et al. [25] (addressing functional impairments, reducing pain and back pain-related disability). However, in a recent systematic review [17], the most frequently reported treatment targets identified by trials of exercise in persistent NSLBP were reducing pain, improving strength and spinal stabilisation. Of those, only pain reduction was prioritised as a treatment target in this 
consensus study, while improving strength was ranked 19 out of 27, and improving motor control (incorporating spinal stabilisation) was ranked 21 out of 27 . This demonstrates a potential shift in contemporary understanding of how exercise may work to reduce NSLBP, and improve function and quality of life.

The psychological constructs of reducing fear of movement, improving self-efficacy, and reducing anxiety and depression were voted for by many participants in the final workshop $(91 \%, 87 \%, 87 \%$, respectively). However, reducing anxiety and depression was not voted to be in the top ten priorities, despite the evidence for exercise in treating depressive symptoms [27]. Both reducing fear of movement and self-efficacy have been shown to partially mediate the relationship between pain and disability in persistent NSLBP $[28,29]$. Recent research on the mechanisms of exercise for chronic musculoskeletal pain suggests reducing fear of movement, improving self-efficacy (both in the final top ten treatment targets), enhancing self-management and improving beliefs, cognitions and attitudes, may explain how painful exercises provide benefit [30]. The psychological benefits of exercise are well-documented [31,32] so the prioritisation of psychological targets by our workshop participants over other performance targets is perhaps not surprising. As the aetiology of persistent NSLBP is increasingly understood to comprise psychological, biomedical and social components [33], the emphasis placed on the psychological targets of exercise for persistent NSLBP seems to make sense. Increasingly, trials are including mediation analyses of these and other psychological constructs to establish whether these treatment targets lie on the causal pathway between the exercise treatment and the outcomes most important to patients (most commonly pain and disability [34-39].

A mediator is a variable which explains how a treatment may work [35]. In certain situations, treatment targets may be the same as or similar to surrogate markers, or intermediate variables (mediators), whereas, in other situations, treatment targets may have more direct effects on outcomes. These terms (treatment targets and mediators) are conceptually different, yet they are terms that are sometimes used interchangeably. It is unknown whether treatment targets have an indirect effect on the causal pathway, similar to the action of a mediator [40], as demonstrated in Fig. 2. For example, increasing functional ability can be reached by decreasing fear of movement. So, in fact, a treatment could be targeted at reducing fear of movement, but the overall aim could be improving function [41]. Distinguishing intermediate targets and final outcomes will also help the exercise and back pain community to better define treatment targets. This will inform how the exercise intervention should be developed and specified, and how the impact of the exercise intervention should be measured (for example, by using terms such as mediating factors and final outcome(s)). It may be that participants in the workshops in this study prioritised treatment targets that they were familiar with (such as reducing pain, increasing function and quality of life, comprising the recommended

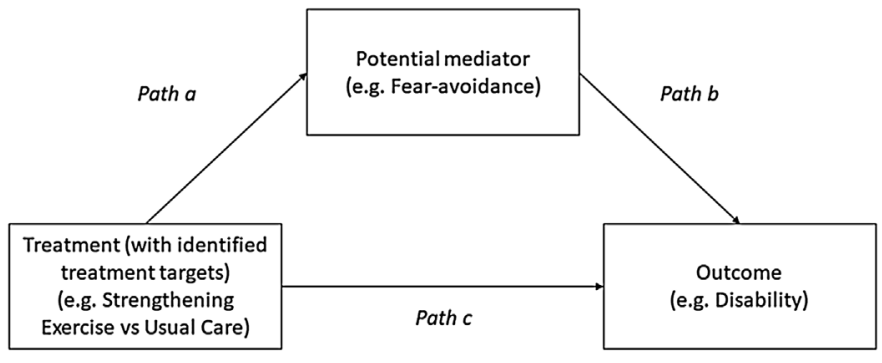

Direct effect of treatment on outcome $=$ path c

Mediating effect $=a b$ (combination of paths $a$ and $b$ )

Total effect $=a b+c$

Fig. 2. Example of a mediation model (modified from Mansell et al. [35]).

core outcome set in this field) rather than considering the likely mechanisms of effect for exercise.

Reducing pain, improving function and quality of life are well-established as important core outcome domains, and are the most commonly reported primary outcomes in RCTs of persistent NSLBP $[42,43]$. When comparing these results, it can be seen that these are the same variables providing evidence that the most important treatment targets of exercise may be those prioritised by the core outcome domains. This suggests that the uptake and acceptance of the core outcome domains by both clinicians and researchers has been widespread, and remain a high priority for people with NSLBP, but their role as treatment targets (or mediators) of exercise interventions remains unclear.

\section{Strengths and limitations}

This consensus study is the first to our knowledge to develop a consensus about the treatment targets for exercise interventions in persistent NSLBP with key stakeholders involved in the use of, development, evaluation and prescription of exercise interventions. Other research on this topic has not included stakeholders [25]. The use of two sequential workshops allowed refinement of the potential treatment targets, informed by a recent systematic review, with both national and international nominal group workshops. Consensus was generated with numerous stakeholders, including people with lived experience of using exercise to manage persistent NSLBP, clinicians prescribing exercise for persistent NSLBP, and researchers who design and evaluate exercise interventions in RCTs. However, this consensus study included only two people with lived experience of persistent NSLBP due to lack of response, but most included researchers and clinicians had themselves experienced back pain. Although the national and international workshop included a sample of clinicians and researchers from across the world, this remains a small sample $(n=39)$, and the results may not be representative of the wider, lower to middle income international community. Further, the majority of the included clinicians were physiotherapists, which may be representative of the breadth of clinicians who use exercise. The 
results obtained may have been different had this workshop been held in a different conference environment with a more clinical focus.

\section{Implications for future research and clinical practice}

This consensus study has explored the most important treatment targets for exercise interventions in persistent NSLBP, with priorities including improving function and quality of life, and reducing pain. This study provides the foundation for further consensus studies involving larger and more diverse groups of participants to generate more robust consensus for exercise as a whole, but may also provide a platform for more targeted consensus workshops aligned to specific exercise types. Overall, 25 targets were ranked and prioritised, which may be useful for future mediation analysis within trials, helping to further understand how exercise works for patients with NSLBP. These targets may be targeted individually when identified at assessment or alongside multiple treatment targets when prescribing, designing, and/or evaluating exercise interventions for persistent NSLBP. By having a greater understanding of the sequential importance of these treatment targets, clinicians may be encouraged to target their exercise intervention to ensure they select the most appropriate exercises to get the most benefit for their patients. As clinicians, by assessing patients for potential contributing factors such as strength deficits, fear avoidance, self-efficacy etc., they can identify priorities for their exercise treatment to target, and thereby select the most appropriate exercise. This can be performed within the framework of shared-decision making, to allow the best fit for each patient.

These agreed treatment targets may guide the design of trials of exercise interventions for persistent NSLBP by helping to target exercise interventions to achievable, measurable outcomes that match the aim(s) of the intervention. Future trial design may benefit from intervention logic models to map out the role of treatment targets, and select the most appropriate outcome domains and measures for complex interventions, such as exercise, with multiple intervention targets $[44,45]$. The identified treatment targets may, therefore, help in the identification of potential mediators of exercise that should be measured in future studies and used in pre-specified mediation analysis within RCTs.

\section{Conclusion}

This consensus study with key stakeholders prioritised increasing function, improving quality of life, reducing pain, meeting patient-specific goals and reducing fear of movement, as the most important treatment targets of exercise interventions for patients with persistent NSLBP. Formal testing of these agreed treatment targets in future research is needed to establish their role on the pathway to improved outcomes.

\section{Key messages}

- This study provides for the first time a consensus of stakeholders about the agreed treatment targets of exercise for persistent LBP.

- Future clinical trials of exercise for persistent LBP would benefit from clear specification of the targets of their exercise interventions, through, for example, intervention logic models.

- Testing whether these agreed treatment targets have a clear role in the pathway to clinical outcomes for patients is now needed.

Ethical approval: Obtained from the Keele University Research Ethics committee for both workshops: on the 17 August 2018 (reference ERP 2393) and an amendment was approved on the 15 April 2019 (reference MH-190019). All participants gave written informed consent before data collection began.

Funding: L Wood was a beneficiary of a Travel Fellowship awarded by the Society of Back Pain Research, UK. L Wood's $\mathrm{PhD}$ is funded by the Primary Care Centre Versus Arthritis, School of Primary, Community and Social Care, Faculty of Medicine and Health Sciences, Keele University. Prof NE Foster is a National Institute for Health Research (NIHR) Senior Investigator and was supported by an NIHR Research Professorship (NIHR-RP-011-015). The views expressed in this publication are those of the authors and not necessarily those of the NHS, the NIHR or the Department of Health and Social Care.

Conflict of interest: None declared.

\section{Appendix A. Supplementary data}

Supplementary material related to this article can be found, in the online version, at doi:https://doi.org/10.1016/ j.physio.2021.03.005.

\section{References}

[1] Stochkendahl MJ, Kjaer P, Hartvigsen J, Kongsted A, Aaboe J, Andersen $\mathrm{M}$, et al. National Clinical guidelines for non-surgical treatment of patients with recent onset low back pain or lumbar radiculopathy. Eur Spine J 2018;27:60-75. Available from: http://link.springer.com/10.1007/s00586-017-5099-2 [cited 4 June 2017].

[2] National Institute for Health and Care Excellence. Low back pain and sciatica in over 16s: assessment and management Assessment and non-invasive treatments Low back pain and sciatica in over 16s [Internet]; 2016. Available from: https://www.nice.org.uk/ guidance/ng59/evidence/full-guideline-assessment-and-noninvasivetreatments-pdf-2726158003 [cited 8 May 2017]. 
[3] Foster NE, Anema JR, Cherkin D, Chou R, Cohen SP, Gross DP, et al. Prevention and treatment of low back pain: evidence, challenges, and promising directions. Lancet 2018;391(10137):2368-83.

[4] Saragiotto BT, Maher CG, Yamato TP, Costa LO, Menezes Costa LOC, Ostelo RW, et al. Motor control exercise for chronic non-specific low-back pain. In: Saragiotto BT, editor. Cochrane Database Syst Rev 2016;(1):CD012004. Available from: http://www.ncbi.nlm.nih.gov/pubmed/26742533 [cited 3 August 2017].

[5] Hayden J, van Tulder M, Tomlinson G. Systematic review: strategies for using exercise therapy to improve outcomes in chronic low back pain. Ann Intern Med 2005;142(9). Available from: http://www.ncbi.nlm.nih.gov/pubmed/15867410 [cited 11 August 2017].

[6] Babatunde OO, Jordan JL, Van der Windt DA, Hill JC, Foster NE, Protheroe J. Effective treatment options for musculoskeletal pain in primary care: a systematic overview of current evidence. In: Fleckenstein J, editor. PLoS One 2017;12(6):e0178621. Available from: http://dx.plos.org/10.1371/journal.pone.0178621 [cited 12 February 2018].

[7] Hayden J, van Tulder MW, Malmivaara A, Koes BW. Exercise therapy for treatment of non-specific low back pain. In: Hayden J, editor. Cochrane database of systematic reviews. Chichester, UK: John Wiley \& Sons, Ltd; 2005.:CD000335. Available from: http://www.ncbi.nlm.nih.gov/pubmed/16034851 [cited 8 May 2017].

[8] Searle A, Spink M, Ho A, Chuter V. Exercise interventions for the treatment of chronic low back pain: a systematic review and meta-analysis of randomised controlled trials. Clin Rehabil 2015;29(12):1155-67. Available from: http://journals.sagepub.com/doi/10.1177/0269215515570379 [cited 25 August 2017].

[9] World Health Organization. WHO I Physical activity. WHO. World Health Organization; 2017. Available from: http://www.who.int/mediacentre/factsheets/fs385/en/ [cited 9 November 2017].

[10] Geneen LJ, Moore RA, Clarke C, Martin D, Colvin LA, Smith BH. Physical activity and exercise for chronic pain in adults: an overview of cochrane reviews. Cochrane Database Syst Rev 2017;4(4):CD011279. Available from: http://www.ncbi.nlm.nih.gov/pubmed/28436583 [cited 3 August 2017].

[11] Helmhout PH, Staal JB, Maher CG, Petersen T, Rainville J, Shaw WS. Exercise therapy and low back pain: insights and proposals to improve the design, conduct, and reporting of clinical trials. Spine (Phila Pa 1976) 2008;33(16):1782-8. Available from: http://www.ncbi.nlm.nih.gov/entrez/query.fcgi?cmd=Retrieve $\& d b=$ PubMed\&dopt=Citation\&list_uids=18628711\%5Cnhttp://graphics . tx.ovid.com/ovftpdfs/FPDDNCOBMECJGJ00/fs046/ovft/live/gv025/ 00007632/00007632-200807150-00013.pdf [cited 2018 January 5].

[12] Justice L, Sofka A, McGinty A. Targets, techniques, and treatment contexts in emergent literacy intervention. Semin Speech Lang 2007;28(1):014-24. Available from: http://www.thieme-connect. de/DOI/DOI?10.1055/s-2007-967926 [cited 2019 February 27].

[13] Fonarow Gregg. Treatment targets in heart failure continued hemodynamics in decompensated heart failure. Rev Cardiovasc Med 2001;2(suppl 2):s7-12. Available from: http://medreviews.com/ sites/default/files/2016-11/RICM_2supp12_s7.pdf.

[14] Schmieder RE, Tschöpe D, Koch C, Ouarrak T, Gitt AK. Individualised treatment targets in patients with type- 2 diabetes and hypertension. Cardiovasc Diabetol 2018;17(1):18. Available from: https://cardiab.biomedcentral.com/articles/10.1186/s12933-0180661-8 [cited 2019 February 26].

[15] Cefalu WT, Kaul S, Gerstein HC, Holman RR, Zinman B, Skyler JS, et al. Cardiovascular outcomes trials in type 2 diabetes: where do we go from here? Ref lections from a diabetes care editors' expert forum. Diabetes Care 2018;41. Available from: http://care.diabetesjournals.org/lookup/suppl/doi:10.2337/dci17-0057/
-/DC1. http://www.diabetesjournals.org/content/diabetes-core-updatepodcasts [cited 24 January 2019].

[16] Kong APS, Yang X, Ko GTC, So W-Y, Chan W-B, Ma RCW, et al. Effects of treatment targets on subsequent cardiovascular events in Chinese patients with type 2 diabetes. Diabetes Care 2007;30(4):953-9. Available from: http://www.ncbi.nlm.nih.gov/pubmed/17259475 [cited 26 February 2019].

[17] Wood L, Foster NE, Lewis M, Bishop A. Exercise interventions for persistent non-specific low back pain - does matching outcomes to treatment targets make a difference? A systematic review and meta-analysis. J Pain 2021;22(2):107-26, http://dx.doi.org/10.1016/j.jpain.2020.04.002.

[18] Moffett JK, Jackson DA, Gardiner ED, Torgerson DJ, Coulton S, Eaton S, et al. Randomized trial of two physiotherapy interventions for primary care neck and back pain patients: "McKenzie" vs brief physiotherapy pain management. Rheumatology 2006;45(12):1514-21.

[19] Garcia AN, Costa L da CMLOP, Hancock MJ, De Souza FS, de O Gomes GVF, De Almeida MO, et al. McKenzie method of mechanical diagnosis and therapy was slightly more effective than placebo for pain, but not for disability, in patients with chronic non-specific low back pain: a randomised placebo controlled trial with short and longer term follow-up. Br J Sports Med 2018;52(9):594-8. Available from: http://bjsm.bmj.com/lookup/doi/10.1136/bjsports-2016-097327.

[20] Harvey N, Holmes CA. Nominal group technique: an effective method for obtaining group consensus. Int $\mathbf{J}$ Nurs Pract 2012;18(2):188-94. Available from: http://doi.wiley.com/ 10.1111/j.1440-172X.2012.02017.x [cited 1 November 2018].

[21] Potter M, Gordon S, Hamer P. The Nominal Group technique: a useful consensus methodology in physiotherapy research. New Zeal J Physiother 2004;32(3):126-30. Available from: http://physiotherapy.org.nz/assets/Professional-dev/Journal/2004November/2004NovHamner.pdf.

[22] Black N. Consensus development methods. In: Pope C, Mays N, editors. Qualitative research in health care. third edition 2006 [chapter 12].

[23] Mc Sharry J, Fredrix M, Hynes L, Byrne M. Prioritising target behaviours for research in diabetes: using the nominal group technique to achieve consensus from key stakeholders. Res Involv Engagem 2016;2(1):14. Available from: http://researchinvolvement. biomedcentral.com/articles/10.1186/s40900-016-0028-9 [cited 1 November 2018].

[24] Mc Sharry J, Fredrix M, Hynes L, Byrne M. Prioritising target behaviours for research in diabetes: using the nominal group technique to achieve consensus from key stakeholders. Res Involv Engagem 2016;2(1).

[25] Rainville J, Hartigan C, Martinez E, Limke J, Jouve C, Finno M. Exercise as a treatment for chronic low back pain. Spine J 2004;4(1):106-15. Available from: http://www.ncbi.nlm.nih.gov/pubmed/14749199 [cited 2 July 2019].

[26] World Health Organization. Towards a common language for functioning, disability and health: ICF. Int Classif 2002;1149:1-22. Available from: http://www.who.int/classifications/ icf/training/icfbeginnersguide.pdf.

[27] Cooney G, Dwan K, Mead G. Exercise for depression. JAMA 2014;311(23):2432-3

[28] Costa CM, Maher CG, Mcauley JH, Hancock MJ, Smeets RJEM. Self-efficacy is more important than fear of movement in mediating the relationship between pain and disability in chronic low back pain. Eur J Pain 2011;15(2):213-9, http://dx.doi.org/10.1016/j.ejpain.2010.06.014. Available from:.

[29] Marshall PWM, Schabrun S, Knox MF. Physical activity and the mediating effect of fear, depression, anxiety, and catastrophizing on pain related disability in people with chronic low back pain. In: Yang J, editor. PLoS One 2017;12(7):e0180788. Available from: http://dx.plos.org/10.1371/journal.pone.0180788 [cited 9 July 2018].

[30] Smith BE, Hendrick P, Bateman M, Holden S, Littlewood C, Smith $\mathrm{TO}$, et al. Musculoskeletal pain and exercise-challenging exist- 
ing paradigms and introducing new. Br J Sports Med 2019;53(14): 907-12.

[31] Stathopoulou G, Powers MB, Berry AC, Smits JAJ, Otto MW. Exercise interventions for mental health: a quantitative and qualitative review. Clin Psychol Sci Pract 2006;13(2):179-93. Available from: http://doi.wiley.com/10.1111/j.1468-2850.2006.00021.x [cited 20 Aug 2018].

[32] Knapen J, Vancampfort D, Moriën Y, Marchal Y. Exercise therapy improves both mental and physical health in patients with major depression. Disabil Rehabil 2015;37(16):1490-5. Available from: http://www.tandfonline.com/doi/full/10.3109/09638288.2014.972579 [cited 17 August 2018].

[33] Falla D, Hodges PW. Individualized exercise interventions for spinal pain. Exerc Sport Sci Rev 2017;45(2):105-15. Available from: http://insights.ovid.com/crossref?an=00003677-201704000-00008 [cited 15 August 2018].

[34] Froud R, Ellard D, Patel S, Eldridge S, Underwood M. Primary outcome measure use in back pain trials may need radical reassessment. BMC Musculoskelet Disord 2015;16(1):88. Available from: http://download.springer.com/static/pdf/3/art\%253A10.1186\%252 Fs12891-015-0534-1.pdf?originUrl=http\%253A\%252F\%252Fbmc musculoskeletdisord.biomedcentral.com\%252Farticle\%252F10.1186 $\% 252$ Fs 12891-015-0534-1\&token2=exp=1497880261 acl=\%252 Fstatic\%252Fpdf\%252F3\%252 [cited 19 June 2017].

[35] Mansell G, Kamper SJ, Kent P. Why and how back pain interventions work: what can we do to find out? Best Pract Res Clin Rheumatol 2013;27(5):685-97. Available from: http://linkinghub.elsevier.com/ retrieve/pii/S1521694213000776 [cited 30 June 2017].

[36] Lee H, Hübscher M, Moseley GL, Kamper SJ, Traeger AC, Mansell G, et al. How does pain lead to disability? A systematic review and meta-analysis of mediation studies in people with back and neck pain. Pain 2015;156(June (6)):988-97, http://dx.doi.org/10.1097/j.pain.0000000000000146.

[37] Lee H, Mansell G, McAuley JH, Kamper SJ. Causal mechanisms in the clinical course and treatment of back pain. Best Pract Res Clin Rheumatol 2017:1-10, http://dx.doi.org/10.1016/j.berh.2017.04.001.
[38] Mansell G, Hill JC, Main C, Vowles KE, van der Windt D. Exploring what factors mediate treatment effect: example of the STarT back study high-risk intervention. J Pain 2016;17(11):1237-45. Available from: http://www.ncbi.nlm.nih.gov/pubmed/27565304 [cited 30 Jun 2017].

[39] Stevens ML, Boyle E, Hartvigsen J, Mansell G, Søgaard K, Jørgensen MB, et al. Mechanisms for reducing low back pain: a mediation analysis of a multifaceted intervention in workers in elderly care. Int Arch Occup Environ Health 2019;92(January (1)):49-58, http://dx.doi.org/10.1007/s00420-018-1350-3. Epub 2018 Sep 1.

[40] Whittle R, Mansell G, Jellema P, Van Der Windt D. Applying causal mediation methods to clinical trial data: What can we learn about why our interventions (don't) work? Eur J Pain 2017;21:614-22.

[41] Woby SR, Watson PJ, Roach NK, Urmston M. Are changes in fearavoidance beliefs, catastrophizing, and appraisals of control, predictive of changes in chronic low back pain and disability? Eur J Pain 2004;8(3):201-10.

[42] Gianola S, Frigerio P, Agostini M, Bolotta R, Castellini G, Corbetta $\mathrm{D}$, et al. Completeness of outcomes description reported in low back pain rehabilitation interventions: a survey of 185 randomized trials. Physiother Can 2016;68(3):267-74. Available from: http://utpjournals.press/doi/10.3138/ptc.2015-30 [cited 16 May 2017].

[43] Froud R, Patel S, Rajendran D, Bright P, Bjørkli T, Buchbinder R, et al. A systematic review of outcome measures use, analytical approaches, reporting methods, and publication volume by year in low back pain trials published between 1980 and 2012: Respice, adspice, et prospice. PLoS One 2016;11(10):1-16.

[44] Rohwer A, Pfadenhauer L, Burns J, Brereton L, Gerhardus A, Booth A, et al. Logic models help make sense of complexity in systematic reviews and health technology assessments. J Clin Epidemiol 2017;83:37-47. Available from: https://doi.org/10.1016/j.jclinepi.2016.06.012.

[45] Hurley DA, Murphy LC, Hayes D, Hall AM, Toomey E, McDonough SM, et al. Using intervention mapping to develop a theory-driven, group-based complex intervention to support selfmanagement of osteoarthritis and low back pain (SOLAS). Implement Sci 2016;11(1):56. Available from: http://implementationscience. biomedcentral.com/articles/10.1186/s13012-016-0418-2. 